\section{NOVA TELLVS}

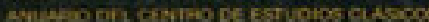

Nova Tellus

ISSN: 0185-3058

novatelu@servidor.unam.mx

Centro de Estudios Clásicos

México

Palazón Mayoral, María Rosa

Ética, amor y locura (Don Quijote según una mirada platónica)

Nova Tellus, vol. 26, núm. 1, 2008, pp. 151-167

Centro de Estudios Clásicos

Distrito Federal, México

Disponible en: http://www.redalyc.org/articulo.oa?id=59115488005

- Cómo citar el artículo

- Número completo

- Más información del artículo

- Página de la revista en redalyc.org

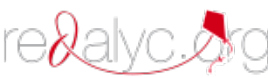

Sistema de Información Científica

Red de Revistas Científicas de América Latina, el Caribe, España y Portugal

Proyecto académico sin fines de lucro, desarrollado bajo la iniciativa de acceso abierto 


\title{
Ética, amor y locura (Don Quijote según una mirada platónica)
}

\author{
María Rosa PALAzÓN MAYORAL \\ Universidad Nacional Autónoma de México \\ mpalazoa@yahoo.com
}

RESUMEN: ¿De dónde surgió el anormal proyecto de Miguel de Cervantes, influido directamente por Erasmo de Rotterdam, de hacer un elogio de la locura? ¿De qué locura se trata? Si hacemos caso omiso de la inmortalidad del alma, en el Fedro y otros fragmentos de Platón encontraremos la semilla griega de esta locura de amor y de belleza, que quiere vivir para los otros y con ellos en instituciones más justas. Amando siempre este anormal-cuerdo vivió loco y murió cuerdo. Quienes no siguen su ejemplo son pragmáticos, ejercen el dominio o son meros pusilánimes.

$$
* * *
$$

ABSTRACT: Where did the abnormal project of Miguel de Cervantes arise, under the direct influence of Erasmus from Rotterdam, to make a praise of madness? What kind of madness is this all about? Even if we pass over the immortality of the soul, the Phaedrus and other works of Plato display the Greek seed of this madness about love and beauty, a seed that wants to live for and with the others whitin a juster institutional frame. Always loving, this abnormal-sensible man lived crazy and died sound. Those who do not follow his example have a pragmatic approach, hold the power or are pusillanimous.

PALABRAS ClAVE: Filosofía, Ética, Literatura, Amor, Belleza.

RECEPCIÓN: 7 de enero de 2008.

ACEPTACIÓN: 19 de mayo de 2008. 


\title{
Ética, amor y locura (Don Quijote según una mirada platónica)
}

\author{
María Rosa Palazón MAYORAL
}

A las palabras de amor/ les sienta bien su poquito/ de exageración (Antonio Machado, "Canciones XI")

Don Quijote, un lío de autores, de traducciones y versiones hermenéuticas, según el propio texto, es también la historia de un loco vivo, más que vivaz, que desde el siglo XVIII nos enamora. Ante tal multitud con el Sócrates-Platónico podemos exclamar: “¿No ves que a poder de las Ninfas, a las que de intento me entregaste, llegaré a caer en un verdadero trance divino?" ¿Por qué este notorio trasvase generacional? Para explicarme desde un punto de vista filosófico-literario, intentaré entremezclar paráfrasis de significativas expresiones cervantinas, ligándolas con textos de Platón que se escaparon del pasado con rumbo al porvenir. Ignoro si este filósofo influyó en Erasmo, cuya ascendencia en Miguel de Cervantes ha sido ampliamente probada. El hecho es que ambos fueron panegiristas de la locura. El origen griego del tema es indiscutible. Las preguntas se suceden en tropel: ¿algún panegirista, quizá latino, tuvo ascendencia en el Elogio de la locura? Lo cierto

\footnotetext{
${ }^{1}$ Platón, Fedro (o sobre la belleza, género moral), 241 E 19 (p. 137): "I shall surely be possessed of the Nymphs to whom you purposely exposed me". La versión de David García Bacca rescata la belleza del diálogo, por lo que facilitaré la búsqueda anotando entre paréntesis las páginas de su edición. Sin embargo, por motivos de contraste del párrafo reproducido, cito también cada pasaje según la edición más completa y la traducción más literal de Phaedrus (edición bilingüe) de Harold North Fowler.
} 
es que, según declaración expresa, Don Quijote fue escrito para diversión de sus lectores; sin embargo, paulatinamente Cervantes engrandeció a un loco de Musas, de Amor y de Belleza, quien, a la par de pitonisas y sibilas, logró adelantarse al porvenir mediante el arte adivinatoria o maniática:

[...] los primitivos institutores de nombres no consideraron la locura o manía ni como vergüenza ni cual oprobio, que en tal caso no hubieran asociado a la más bella de las artes, a la discernidora del porvenir, ese mismo nombre y llamándola [...] arte maniática o adivinatoria. Al contrario; por ser bella, cuando por lotería divina sobreviene, le impusieron, convencidos, tal nombre de manía. ${ }^{2}$

En estas páginas sólo pretendo señalar las confluencias de esta a-normalidad y de la ética de dos autores: un camino bastante inexplorado, lleno de maleza que juzgo necesario desbastar.

Según Alasdair McIntyre (Three Rival Versions of Moral Enquire), ${ }^{3}$ el filósofo no puede argumentar sobre la moral, si no recurre a fuentes ajenas a la filosofía: en las narraciones literarias encuentra propuestas importantes porque ejemplifican con una historia acciones éticas, morales, inmorales o amorales, incomprensibles al margen de los textos que especifican quién, cómo y para qué las realiza, destacando las intenciones, los motivos y las circunstancias que explican las acciones en cuestión, y esto independientemente de que la obra use la complexión de no-verdad o fantasía. Tales acciones locas están condicionadas por el pasado y sus tradiciones míticas; por ejemplo, el Paraíso Perdido, El Buen Salvaje y en este caso la Edad de Oro, propuestas utópicas, siempre prospectivas, futuristas que "reviven" y "hacen palabra" debido a que su receptor las con-

\footnotetext{
${ }^{2}$ Phdr., 244 C 22 (p. 147): "those men of old who invented names thought that madness was neither shameful not disgraceful; otherwise they would not have connected the very word mania with the noblest of arts, that which foretells the future, by calling the manic art".

${ }^{3}$ Passim.
} 
sidera actualizables. Locura paralela a la quijotesca, cuyo final sostiene que nuestra vida deja su condición ontológica duradera, se apaga, cuando pierde los ideales de un mañana más justo socialmente. Rescatar qué dijo Cervantes sobre un "loco cuerdo" hace cuatrocientos años, es rescatar el espíritu comunitario, que manifestaron los primeros Padres de la Iglesia, grandes filósofos, Marx incluido, y hasta los chamanes, cuyos viajes simbólicos hasta donde están los antepasados y los dioses tuvieron y aún tienen el sentido de reunir en la paz y la concordia lo que separó la muerte. ${ }^{4}$

Si concebimos al ser humano como agresivo y amoroso, poseedor de dos cuadrigas del alma; una positiva y la otra negativa (adapto, libremente, la metáfora platónica), ${ }^{5}$ nuestra libertad socializada depende de que, mirando a los caballos de torcida y fea testuz, llevemos a término el discrimen. Prudencia que faltó a Don Quijote porque, sabiendo que hacer el bien a los malos es echar agua en el mar, cayó siempre en las trampas de sus enemigos. No obstante, una lección de esta obra es que demos el mando a los caballos bellos y buenos, puliéndolos, esculpiéndolos, evitando nuestra única culpabilidad real, a saber, la insociable sociabilidad o daño hecho voluntariamente al inocente.

Actualicemos otras nociones griegas sobre las dos especies de locura. En la natural, la de Furias, única mala, el yo herido intenta protegerse de los perversos que, ejerciendo su poder de dominio, le han negado el derecho a ser feliz, haciéndolo víctima del inmoral pragmatismo de que trata al otro, al ame-

\footnotetext{
${ }^{4}$ Cf. Phdr., 244 E 22 (p. 147).

${ }^{5}$ Cf. Phdr., 246 A 25 y ss. (p. 153): "We will liken the soul to the composite nature of a pair of winged horses and a charioteer. Now the horses and charioteers of the gods are all good and of good descent, but those of other races are mixed; and first the charioteer of the human soul drives a pair, and secondly one of the horses is noble and of noble breed, but the other quite the opposite in breed and character. Therefore in our case the driving in necessarily difficult and troublesome".
} 
nazante distinto y rebelde, como un medio y nunca como un fin, dice Kant, ${ }^{6}$ hasta que ese yo confundido y perplejo se aísla entre las murallas protectoras del repetitivo delirio, en una vaciedad que le carcome el seso y desnata el entendimiento, ${ }^{7}$ asegura Don Quijote, es decir, acaba hundido en el solipsismo, en un discurso que ha cortado los lazos comunicativos. Tal es la locura que, dice Erasmo, sube de los infiernos cada vez que las Furias lanzan su cabellera de serpientes y su petrificante mirada psicótica, ${ }^{8}$ y esto de petrificante se debe a que, según creencia popular, las serpientes dejan como piedra o hipnotizan a quien las mira. Únicamente se puede intentar atajar la carrera hacia la nada de este yo infeliz, ofreciéndole los maravillosamente placenteros momentos del amor, del juego y de las lúdicas artes, actividades socializadoras o participativas.

En Don Quijote de la Mancha estamos ante una serie de aventuras que ostentan el buen decir, un juego lingüístico apasionante que apela a lo intelectivo, emotivo y a la sensibilidad de su receptor, quien también interpreta desde una posición semejante. Don Quijote, nuestro prójimo, es, pues, un inspirado:

Pero hay una tercera clase de posesión y locura adivinatoria: la que de las Musas viene. Si se apodera de un alma delicada y pura, la despierta, la embriaga de odas y de toda clase de poesía; ella fue quien embelleció tantas y tantas obras de los antiguos y quien educa a su posteridad. ${ }^{9}$

El difuso por difundido poder de dominio, que clava en el yo las saetas del remordimiento y la culpa, minimiza la rebelión de "ovejas" con el ardid de llamarlas locas, des-adaptadas, a-

\footnotetext{
${ }^{6}$ Kant, Crítica del juicio, § 59, pp. 203-206.

${ }^{7}$ Cervantes, Don Quijote, II, XLII.

${ }^{8}$ Erasmo de Rotterdam, Elogio de la locura, 38, p. 83.

${ }^{9}$ Phdr., 245 A 22 (p. 149): "And a third kind of possession and madness comes from the Muses. This takes hold upon a gentle and pure soul, arouses it and inspires it to songs and other poetry, and thus by adorning countless deeds of the ancient educates later generations".
} 
normales, o fuera de la norma, como le ocurrió en aquella histórica Edad de Hierro al alma noble y generosa, luz y espejo que adornó la Mancha, ${ }^{10}$ el calvatrueno y cincuentón Don Quijote, un loco bizarro, con abundancia de lúcidos intervalos, ${ }^{11} \mathrm{y}$ muy comedido, excepto cuando interpretó algunas circunstancias bajo indicadores de las novelas de caballería ${ }^{12}$ que le desnataron el entendimiento. Sí, por no mirar los caballos negros propios y ajenos, Don Quijote fue humillado por muchos de sus contemporáneos en esta Edad en que crujen los damascos y bordados, triunfa el vicio sobre la virtud, y la presuntuosa arrogancia sobre la autenticidad. Tan mala época es que fue perseguido asiduamente por Ginés de Pasamonte, uno de los galeotes que liberó. Edad que impuso la redundante fiebre de la guerra, la ambición del oro y los neg-otia, o negación de los creativos ratos de ocio, obligando a todos cada día más a un ritmo de vida sin sentido y atolondrado. Edad de un metal que, a diferencia del oro, se corrompe, porque su orden insano estimula a quienes compiten, recelan y envidian, obligando a los bien intencionados a defenderse de un sin número de triquiñuelas y de Bachilleres Carrasco, la normalidad adaptada a una etapa repleta de injusticia, ajena a la ética.

En la etapa histórica del Hierro, todo idealista es blanco de ataques inmisericordes, de los cuales saca, según fórmula simbólica cervantina, una oreja de menos, las persecuciones y castigos de la gente soez y mal nacida ${ }^{13}$ que milita en fuerzas represivas como la Santa Hermandad, ${ }^{14}$ o saca el menosprecio de sus verdades como sandeces y chanzas intrascendentes, dignas de risa y de lástima. En suma, según el mito citado, el cual había sustentado Platón en el Fedro, es la Edad en que

\footnotetext{
${ }^{10}$ Don Quijote, II, XLII.

${ }^{11}$ Ibid., II, XVIII.

12 Ibid., I, XLIX.

${ }^{13}$ Ibid., I, XXXVIII.

${ }^{14}$ Ibid., I, X.
} 
los cocheros de las almas colectivas han soltado las riendas al caballo resabiado, adulador, falaz, disparejamente compuesto, grueso de testuz, sanguinario, insolente, duro de cerviz y obediente al látigo. Por el contrario, "es el caso que los máximos de entre los mayores bienes nos nacen por accesos de locura". 15

El "alma de cántaro" de Don Quijote no tuvo nada de bellaca, artificiosa ${ }^{16}$ ni mentecata, sino "mucha sal en la mollera" que lo hizo un razonador discreto y tan creativo o poeta que todo lo alcanzó o supo. ${ }^{17}$ Fue un vehemente loco de amor por voluntad propia.

El loco cervantino estuvo tan fuera de los usos de su tiem$\mathrm{po}^{18} \mathrm{y}$ del nuestro que, funcionando como un juego de espejos, enquijotó la vida y nuestra loca parte bella o virtuosa, más perseguida por los malos que querida por los buenos. ${ }^{19}$ Juego de espejos porque sabemos, con Platón y Erasmo, que los mayores bienes son dones nacidos en tales accesos de locura: "Nosotros demostraremos justamente lo contrario: que tal locura es un don de los Dioses para suprema bienaventuranza de ambos" (de Sócrates, de Fedro o de ti y de mí). ${ }^{20}$

El cochero del alma de Don Quijote dio rienda suelta al caballo de figura esbelta, de miembros equilibrados, ligeramente aguileño, erguido de cerviz, mesurado y pudoroso, que bebió néctar y ambrosía. Puso en escena la kalokagathía, o confluencia de lo bueno y lo bello, o lo espontáneo y armoniosamente bueno. Caracterización que nos lleva a la otra especie de locura, la buena, o transformación divina o utópica, la que

\footnotetext{
${ }^{15}$ Phdr., 244 A 22 (p. 145): "but in reality the greatest of blessings come to us through madness, when it is sent as a gift of the gods".

${ }^{16}$ Don Quijote, II, XII.

${ }^{17}$ Ibid., I, XVIII, y II, XVII.

${ }^{18}$ Ibid., II, XX.

${ }^{19}$ Ibid., I, XLVII.

${ }^{20} P h d r$., 245 C 23: "We, on our part, must prove that such madness is given by the gods for our greatest happiness".
} 
imagina desde ningún lugar ni tiempo, ajena a los comportamientos habituales. En el Fedro, Platón la divide en cuatro: la de Apolo o adivinadora; la de Dionisio o mística; la poética o inspiración de Musas, y la de Venus y Eros, madre e hijo, locura a la que otorga supremacía.

[...] hay dos especies de locura: una que proviene de enfermedades humanas, otra producida por una transformación divina de nuestros comportamientos habituales [...]. Y dividimos la locura divina en cuatro partes adscritas a cuatro dioses, atribuyendo a Apolo la inspiración adivinadora, a Baco la iniciadora en misterios, la poética a las Musas, la cuarta a Venus y a Amor, proclamando por fin la supremacía de la amorosa locura. ${ }^{21}$

Centrémonos en las dos últimas y en su mutua dependencia. Hace ya mucho, en los sagrados inicios, escribe Platón, las cigarras trajeron el canto con placer tan fuerte que, cantando y cantando, se descuidaron de comer. Al morir, las Musas, en particular las canoras Terpsícore y Erato, inspiraron a los músicos y los límpidos cantos amorosos de los poetas, amantes de lo bello ${ }^{22}$ que con su arte maniática saben atisbar la belleza, porque "sólo a la Belleza ha caído en suerte la de ser de vez (sic) lo más esplendoroso y lo más amable". ${ }^{23}$ La fórmula platónica es, pues, que el amor es una clase de apetencia por lo bello orientada por el placer, que entre poetas y escritores significa cantar afinadamente y saber escuchar el afinado canto o el límpido timbre de las Musas canoras, ${ }^{24}$ porque no hay

${ }^{21}$ Phdr., 265 A 48 y 265 B 48 (pp. 211 y 213): "there are two kinds of madness, one arising from human diseases, and the other from a divine release from the customary habits. [...] And we made four divisions of the divine madness, ascribing them to four gods, saying that prophecy was inspired by Apollo, the mystic madness by Dionysus, the poetic by the Muses, and the madness of love, inspired by Aphrodite and Eros, we said was the best".

${ }^{22}$ Phdr., 249 D 30 (p. 163).

${ }^{23}$ Phdr., 250 D 31 (p. 165): "beauty alone has this privilege, and therefore it is most clearly seen and loveliest".

${ }^{24}$ Phdr., 237 B 13 (p. 123). 
el poeta primero y los segundones, sino buen arte y mal arte (aunque siempre los acudidos se corrigen a posteriori).

Cierto, hay efímeros relumbrones poéticos que Platón compara con el labrador que durante el verano en el jardincillo de Adonis sembraba en cestillos, vasos y conchas. En ocho días brotaban unas plantas para gracia de la fiesta, simbolizando con su prematuro final el del hijo amado de Venus. ${ }^{25}$ Un poeta que ama su oficio siembra en terreno apropiado, dejando que la sementera llegue a su sazón en el jardín de las Letras, sin que escriba en agua negra discursos impotentes. Al menos personalmente se deleitará con sus brotes, que nunca son meros refrigerios, sino palabras que se bastan a sí y fecundan a su tiempo otras semillas. Abro un paréntesis que invita a meditar. Este símil entre el poeta, versificador o prosista, y el jardinero me hace pensar en aquella apostilla de Diótima, recogida en el Banquete, contra la elitización de las artes:

[...] sabes de buen saber que poesía es algo polimorfo, que toda causa que haga pasar una cosa cualquiera del no ser al ser es poesía, de modo que las manipulaciones de todas las técnicas son poesía, y los menestrales, poetas. ${ }^{26}$

El amor a lo que se compone para el otro hace poetas. ${ }^{27}$ En este sentido, el amor es la excelsa fuerza de lo que llega al bien.

La composición de la prosa o del verso porta un razonamiento y un azaroso trabajo juguetón que revuelve las palabras, uniéndolas o separándolas. Combinación que impide que se fuerce al amante de las palabras a decir lo que se le exige por encargo. Ha de permitírsele que construya su discurso como un ser vivo duradero, o discurso convenientemente armonizado en sus partes medias y en sus extremidades. Jamás es buen arte el canto sin pies ni cabeza. Un poema, igual que

\footnotetext{
${ }^{25}$ Phdr., 276 B 61 (p. 247).

${ }^{26}$ Pl., Symp. 205 C.

${ }^{27}$ Ibid., 197 A.
} 
las afecciones del alma, se entrega como un todo de forma y contenido, como lo inseparable e inalterable.

Desde que nació el Amor, andan las cosas de los dioses por manera de la Belleza. Nieto de Inventiva, es rico en tretas y recursos. Es don que sorprende y gracia admirable, termina Platón en el Fedro.

El amor - erotismo - no es, pues, cordura. Tiene mucho de intemperancia: García Bacca la sintetiza en tres, es algo: "plurívoca, plurimembre y multiforme" ${ }^{28}$ que arrastra. Erasmo observa que los amantes andan tan fuera de cabales, desvarían sin poder contenerse. ${ }^{29}$ Bajo las flechas de Eros las cosas que antes parecieron insignificantes se miran adorables. Por desvaríos de amor, el amado es la persona más gallarda, honesta, sin tacha y la más hermosa del universo. Calificativos que infunden valor al amante y lo ayudan a sobrevivir. Según informa la voz omnisciente del autor, hacer de Aldonza Lorenzo, la mejor saladora de puercos de su región natal, una sublimada Dulcinea, nombre sonoro de gran dama, sólo quiere decir que Don Quijote está enamorado. Igual que su amor por Rocinante, su maltrecho animal compañero, lo transforma en un corcel tan magnífico como el Bucéfalo de Alejandro o el Babieca del Cid.

Las flechas empapadas de las sustancias delirantes de Eros caen estrepitosamente donde se coarta la felicidad y el engrandecimiento del supuesto amado o amada. Y esto porque amor y belleza son libertad y respeto. Donde hay fealdad, no hay amor. La fealdad es lo moralmente pequeño e inconfesable. Lo siniestro que nace muerto. En cambio, la amorosa Belleza engendra vida contra el oprobio y deshace la incuria. Entre amantes, la malevolencia, los celos, la envidia, el aislamiento del otro o de la otra para que sean huérfanos, y demás feas artimañas tan sólo son espectáculos de la pequeñez. En la pareja, el dominante, motivado por su inseguridad, emulando

\footnotetext{
${ }^{28}$ Traducción libre de Platón, Phdr., 238 B 14 (p. 127).

${ }^{29}$ Paráfrasis del Elogio de la locura, 16, pp. 54-55; 15, 52; 19, p. 57.
} 
el aprecio que tienen los lobos por los corderos, fuerza al otro a la pasividad, lo mantiene en estrecha vigilancia, y lo llena de reproches, que díscolamente aminora con elogios extemporáneos. El dominante, según Platón, acaba siendo la molesta y dañina sobrecarga de un desertor del amor que obliga a su víctima a regresar a sus cabales, a poner en el fiel de la balanza por un lado lo volátil del amor, la presteza del amante que hace al amado gracia de sí en obras y palabras, o sea, la querencia cumplida. Y por el otro, la pesadez del odio pesimista que le está cayendo encima. Además, lo invita a hacer efectiva la inscripción del Templo de Delfos que rezaba "Conócete a ti mismo" con la pregunta ¿cómo, creyéndome vencido por el amor, he logrado ser vencedor de mí mismo?

La prenda segura del amante de lo venidero, conservando para siempre la gratuidad, es el don ético-amante que mira hacia un futuro más justo con y para los otros. Sócrates invoca una plegaria a Pan para que la belleza interior consuene amigablemente con las "pertenencias" exteriores, porque "entre amigos todo es común". ${ }^{30}$ Así, Don Quijote no amó a Dulcinea como un pedigüeño de fama, de vanagloria y del lucimiento por tener la compañía de alguien en la "edad en flor", ${ }^{31}$ sino que la vio cuatro veces y durante una docena de años la amó en silencio, con una lealtad inquebrantable. Pero no creo que el suyo fuera un amor casto. Unamuno me ha convencido. ${ }^{32}$

\footnotetext{
${ }^{30}$ Phdr., 279 C 64 (p. 259).

${ }^{31}$ Don Quijote, II, XL.

${ }^{32}$ Unamuno, Vida de Don Quijote y Sancho, p. 226. Cf. Phdr., 240 C-D 17 (p. 133): "Es sentencia en antiguas palabras que los de una edad con los de la misma se deleitan, porque, a mi parecer, la igualdad de años lleva la de placeres y semejanza trae consigo amistad; y, no obstante, tiene sus límites tal camaradería. Añádase que, según dicho universal, lo forzado se vuelve siempre pesado, lo cual, aun dejando aparte desigualdades en edad, vale sobre todo del trato entre amante y doncel, porque amante mayor de edad no suelta de buena gana al amado menor, ni de día ni de noche, y el amado se siente empujado, constreñido, aguijoneado y conducido por haberse dado en delicioso pasto a ojos, oídos y tacto de quien, por todos los sentidos, quisiera estar sintiéndole; y así queda el amado sujeto al amante
} 
En un hombre que en aquella época histórica frisaba la vejez, sus sentimientos tuvieron una fuerte carga de sensualidad. La continencia no borró el deseo carnal, sino que cerró sus labios con un sello de bronce. ${ }^{33}$

En las últimas líneas he insinuado que, así como Platón me parece muy ciego a las simbologías cuando acusa a los mitopoetas de inventar las desconcertantes y "nefastas" fantasmagorías de los Hipocentauros, la Quimera, las Gorgonas, los Pegasos y otros "esperpentos", no se olvida de que las composiciones poéticas y las almas son un todo, un inseparable sistema, ni tampoco se olvida de que el amor es apetencia, y esto porque somos unidad viva de cuerpo y alma. La querencia corporal de los amantes no está reñida con su amistad. No, no hay un Eros alado en ascendente marcha hacia las alturas, o casa de los dioses, encarcelado en un pesado cuerpo perecedero: hay un mortal Eros demonio, emparentado con Expedito y Apurada, esto es, pobre y necesitado de complemento sexual. Pero ese Amor no desciende, alejado de la fecundidad creadora del Amor, hijo y padre de la Venus celestial. Es la otra cara de la moneda llamada vida.

Tampoco el amor a las ideas logra tan sólo mediante las capacidades innatas acceder al conocimiento, porque entonces se limitaría a ser re-conocimiento. Los herederos de las cigarras, o versificadores, alcanzan el manejo de las técnicas poéticas, con su faceta sintáctica y semántica, escuchando al otro, aprendiendo mediante el diálogo con el otro y lo otro, reconociendo que únicamente saben que no saben.

con los bien ajustados vínculos del placer"; en la traducción de Fowler: "I suppose, equality of age leads them to similar pleasures and through similarity begets friendship [...]. Now compulsion of every kind is said to be oppressive to every one, and the lover not only is unlike his beloved, but he exercises the strongest compulsion. For he is old while his love is young, and he does not leave him day or night, if he can help it, but is driven by the sting of necessity, which urges him on, always giving him pleasure in seeing, hearing, touching, and by all his senses perceiving his beloved so that he is glad to serve him constantly".

${ }^{33}$ Unamuno, op. cit., p. 226. 
Por último, hablemos de los disparos del amor, de lo bello moralmente que van a clavársenos en el alma, según expresión de Demócrito citada en el Banquete, ejemplificando el asunto con las virtudes de Don Quijote, una bella persona que, como Sancho Panza, hemos llegando a querer como a las "telas" de nuestro corazón. ${ }^{34}$ Decimos que una persona es bella cuando manifiesta la espontánea gracia y, sobre todo, la dignidad (Anmut y Würde, en alemán: Schiller). Don Quijote personifica el amor que también es superabundancia gratuita - graciosa-, magnificencia o don de sí. En su esencia, el amor caridad es un don, un regalo. Un prodigio que desconcierta a los mismos dioses. ${ }^{35}$ Porque, dirá Plotino, ${ }^{36}$ brota del Uno, del Dios que, para Erasmo, en sus raptos de sabia locura reparte bienes sin pedir a cambio ofrendas ni ceremonias. Pero no hemos de mirar tan alto: la loca o a-normal parte bella de nosotros mismos, basándose en su autoestima - porque únicamente es ruin quien por ruin se tiene,$-{ }^{37}$ o centrada en el yo, en su obrar, se polariza o descentra. Tal es la "fineza del negocio" de quien ha decidido volverse loco y desatinar en toda ocasión, a sabiendas de que en esta Edad de Hierro irá por lana y volverá trasquilado, ${ }^{38}$ porque la mayoría de sus empresas le saldrán torcidas. ${ }^{39}$

La locura de amor del utopista por decisión propicia que su acción concuerde medios y fines. Será valiente, liberal, sincero y veraz, y esto último porque esta clase de locura evita lo más posible que seamos el actor teatral que con una lengua dice la verdad y con la otra aquello que le conviene. También esta quijotesca o amorosa parte bella de nosotros es amante

\footnotetext{
${ }^{34}$ Don Quijote, II, XIII.

${ }^{35}$ Pl., Symp., 198 A.

${ }^{36}$ Plotinus, Enn., V, 2, 1; VI, 9, 1 у 6.

${ }^{37}$ Don Quijote, I, XXI.

${ }^{38}$ Ibid., I, VII.

${ }^{39}$ Ibid., I, L.
} 
de lo justo y enemiga de las perversiones clasistas, sexistas y racistas, ávidas de poder de dominio, porque, al fin, una bella persona desnuda nació y desnuda se halla, de modo que ni pierde ni gana. ${ }^{40}$ En resumen, una bella persona se esfuerza por estar fuera del pragmatismo instrumental, tratando al otro como fin y no sólo como un medio.

Desgraciadamente, Cervantes deja en al aire el pútrido aroma de la muerte. Es decir, la victoria de Tánatos. La recuperación de la salud mental de Don Quijote, su regreso a la sensatez, al pragmatismo del hierro es señal inequívoca de que lo está acabando la melancolía o depresión. El epitafio de ese hombre de bien, de esta maravillosamente ejemplar bella persona, fue "morir cuerdo y vivir loco". ${ }^{41}$ Por lo tanto, sólo me resta hacer votos para que Eros, Venus y las Musas nos sigan agraciando con sus locuras porque: "es el caso que los máximos de entre los mayores bienes nos nacen en accesos de locura, dada cual don divino certificado [...]". ${ }^{42} \mathrm{Y}$ escuchad poetas: "quien se llegare a las puertas de la poesía sin estar tocado de locura de Musas, confiado en que la técnica le bastará para ser poeta, es un fracasado, aparte de que la poesía del perito palidece frente a la de quien está poseso de locura de Musas". 43

\footnotetext{
${ }^{40}$ Ibid., II, VI.

${ }^{41}$ Ibid., II, LXXIV.

${ }^{42}$ Phdr., 245 C 23 (p. 149): "We, on our part, must prove that such madness [de Amor] is given by the gods for our greatest happiness".

${ }^{43}$ Phdr., 245 A 22 (p. 149: "But he who without the divine madness comes to the doors of the Muses, confident that he will be a good poet by art, meets with no success, and the poetry of the sane man vanishes into nothingness before that of the inspired madmen".
} 


\section{BIBLIOGRAFÍA}

Cervantes SaAvedra, Miguel de, El ingenioso hidalgo Don Quijote de la Mancha I y II, John Jay Allen (ed.), México, Rei-México (Letras Hispánicas), 1994 (1ª reimp.).

ERASmo de RotTerdam, Elogio de la locura, trad., introd. y notas Pedro Rodríguez Santidrán, Madrid, Alianza Editorial (El Libro de Bolsillo, Humanidades 4403), 2006 (6a. reimp.).

Foucault, Michel, Historia de la locura en la época clásica, Juan José Utrilla (trad.), México, Fondo de Cultura Económica (Breviarios, 191), 1994 (6a reimp.).

Kant, I., Crítica del juicio, Manuel García Morente (trad.), Madrid, Espasa-Calpe, 1977.

KLEIN, Melanie, Obras completas 3. Envidia y gratitud y otros trabajos, V. S. de Campo, D. Dubcovsky, V. Fischman, H. Friedenthal, A. Koremblit, D. Liberman, R. Malfé, M. Rosenblatt, N. Watson, S. Zysman (trads.), R. E. Money Kyrle (trad. del prefacio) y Adolfo Negroto (trad. de las notas aclaratorias), Barcelona, Paidos, 1994 (2 $2^{\text {a }}$ reimp.).

MCINTYRE, Alasdair, Three Rival Versions of Moral Enquiry: Encyclopaedia, Genealogy, and Tradition being Gifford Lectures delivered in Edinburgh in 1988, Notre Dame, Indiana, University of Notre Dame Press, 1990.

Platón, Hipias Mayor. Fedro (o sobre la belleza. Género moral), introducciones, versión directa y notas Juan David García Bacca, México, Universidad Nacional Autónoma de México (Bibliotheca Scriptorum Graecorum et Romanorum Mexicana. Obras Completas de Platón), 1945.

-, Plato in Twelve Volumes I. Euthyphro. Apology. Crito. Phaedo. Phaedrus, by Harold North Fowler, London/ Cambridge Massachusetts, William Heinemann Ltd/Harvard University Press, MCMLXXI.

-, Obras completas. Banquete. Ión, versión, introducción y notas Juan David García Bacca, México, Universidad Nacional Autónoma de México (Bibliotheca Scriptorum Graecorum et Romanorum Mexicana), 1944.

Plotinus, Enneads, vol. V, ed. A. H. Armstrong, Cambridge, Cambridge University Press, 1984.

SCHILLER, Friedrich, Kallias. Cartas sobre la educación estética del hombre, edición bilingüe, Jaime Feijoo (estudio), traducción Jaime Feijóo y Jorge Seca, Barcelona, Anthropos/ Ministerio de Educación 
NOVA TELLVS, 26•1, 2008, pp. 151-167

y Ciencia (Textos y Documentos. Clásicos del Pensamiento y de las Ciencias, 8), 1990.

Unamuno, Miguel de, Vida de Don Quijote y Sancho, Alberto Navarro (ed.), Madrid, Cátedra (Letras Hispánicas), 1988. 